\title{
FGF5 Regulates Schwann Cell Migration and Adhesion
}

\author{
Bing Chen ${ }^{1 *}$, Rong $\mathrm{Hu}^{2}$, Qing Min ${ }^{3}$, Yankun $\mathrm{Li}^{3}$, David B. Parkinson ${ }^{4}$ \\ and Xin-peng Dun ${ }^{3,4,5}$
}

${ }^{1}$ Department of Neurology, The Affiliated Huai'an No.1 People's Hospital of Nanjing Medical University, Huai'an, China, ${ }^{2}$ School of Traditional Chinese Medicine, Southern Medical School, Guangzhou, China, ${ }^{3}$ School of Pharmacy, Hubei University of Science and Technology, Xianning, China, ${ }^{4}$ Peninsula Medical School, Faculty of Health, University of Plymouth, Plymouth, United Kingdom, ${ }^{5}$ The Co-innovation Center of Neuroregeneration, Nantong University, Nantong, China

\section{OPEN ACCESS}

Edited by:

Stefania Ceruti,

University of Milan, Italy

Reviewed by:

Euan Robert Brown,

Heriot-Watt University,

United Kingdom

Fei Ding,

Nantong University, China

Kazuaki Nakamura,

National Center for Child Health and

Development (NCCHD), Japan

${ }^{*}$ Correspondence:

Bing Chen

chenbing2007@163.com

Specialty section:

This article was submitted to

Non-Neuronal Cells,

a section of the journal

Frontiers in Cellular Neuroscience

Received: 26 March 2020

Accepted: 06 July 2020

Published: 04 August 2020

Citation:

Chen B, Hu R, Min Q, Li Y,

Parkinson DB and Dun $X$

(2020) FGF5 Regulates Schwann Cell

Migration and Adhesion.

Front. Cell. Neurosci. 14:237.

doi: 10.3389/fncel.2020.00237
The fibroblast growth factor (FGF) family polypeptides play key roles in promoting tissue regeneration and repair. FGF5 is strongly up-regulated in Schwann cells of the peripheral nervous system following injury; however, a role for FGF5 in peripheral nerve regeneration has not been shown up to now. In this report, we examined the expression of FGF5 and its receptors FGFR1-4 in Schwann cells of the mouse sciatic nerve following injury, and then measured the effects of FGF5 treatment upon cultured primary rat Schwann cells. By microarray and mRNA sequencing data analysis, RT-PCR, qPCR, western blotting and immunostaining, we show that FGF5 is highly up-regulated in Schwann cells of the mouse distal sciatic nerve following injury, and FGFR1 and FGFR2 are highly expressed in Schwann cells of the peripheral nerve both before and following injury. Using cultured primary rat Schwann cells, we show that FGF5 inhibits ERK1/2 MAP kinase activity but promotes rapid Schwann cell migration and adhesion via the upregulation of $\mathrm{N}$-cadherin. Thus, FGF5 is an autocrine regulator of Schwann cells to regulate Schwann cell migration and adhesion.

Keywords: FGF5, receptors, peripheral nerve injury, Schwann cell, migration, adhesion, $\mathrm{N}$-cadherin

\section{INTRODUCTION}

The fibroblast growth factor (FGF) family includes 22 structurally related polypeptides that are highly conserved in mammals (Beenken and Mohammadi, 2009; Ornitz and Itoh, 2015). FGF1-22 proteins bind with high affinity to four FGF receptors, FGFR1-4, and FGFR1-4 activation has been implicated in multiple biological processes in mammals including cell proliferation and differentiation during development and tissue repair (Ornitz and Itoh, 2015). Mutations in FGF or FGFR genes cause developmental and genetic diseases in many different tissue types (Beenken and Mohammadi, 2009; Ornitz and Itoh, 2015). Numerous studies have also reported roles for FGFs in tissue regeneration and repair, underlying the importance of FGF-FGFR signaling in tissue homeostasis (Nunes et al., 2016; Charoenlarp et al., 2017; Maddaluno et al., 2017). The activation of a specific FGF-FGFR signaling and subsequent biological activities depends on the spatial and temporal expression pattern of each FGF ligand and their receptors (Beenken and Mohammadi, 2009; Ornitz and Itoh, 2015). 
We are interested in the molecular mechanism of peripheral nerve regeneration following injury, and among all the FGFs, FGF5 is highly up-regulated in the distal nerve in response to injury (Moscoso et al., 1998; McGeachie et al., 2001; Scarlato et al., 2001); this striking increase suggests a role for FGF5 in the regulation of peripheral nerve repair.

The FGF5 gene was first isolated as a human oncogene by a DNA rearrangement accompanying the transfection of fibroblasts with human tumor DNA (Zhan et al., 1987, 1988). FGFs can be arranged into seven subfamilies based on a phylogenetic analysis, and FGF5 resides in the FGF4 family, which is comprised of FGF4, FGF5, and FGF6 (Ornitz and Itoh, 2015). All members of this subfamily are secreted proteins with cleavable N-terminal signal peptides that mediate biological responses as extracellular proteins by binding to and activating FGFR1-4. Despite high expression of FGF5 in both embryonic and adult tissues (Haub et al., 1990; Haub and Goldfarb, 1991), FGF5 knockout mice are viable (Hébert et al., 1994) and the only phenotype that has been observed in FGF5 knockout mice was abnormally long hair (Hébert et al., 1994). This phenotype is identical to homozygous mice for the spontaneous mutation angora (go) mice (Hébert et al., 1994). Crossing of FGF5 knockout mice and go mutation mice failed to complement the long hair phenotype, resulting in the identification of the go mutant as a mutant allele of FGF5 (Hébert et al., 1994).

FGF5 is detectable in adult rat skeletal muscle and its expression increases in skeletal muscle following denervation (Hughes et al., 1993; McGeachie et al., 2001). In vitro analysis showed that FGF5 could promote the survival of embryonic motor neurons, therefore, FGF5 has been proposed as a musclederived regulator of motor axon regeneration (Hughes et al., 1993). However, in vivo studies have failed to show defects in muscle reinnervation in FGF5 null mice (Moscoso et al., 1998). Furthermore, in vivo studies in go homozygotes mice not only found that endogenous FGF5 is not transported in motor axons but also failed to reveal any loss of motoneurones (McGeachie et al., 2001). Later studies confirmed that FGF5 protein was expressed in the terminal and non-terminal Schwann cells but not in muscle fibers (McGeachie et al., 2001). Scarlato et al. (2001) also showed that nerve injury resulted in an increase of FGF5 in the Schwann cells of the distal nerve. Schwann cells have been shown to express FGFR1-3 (Meisinger and Grothe, 1997; Grothe et al., 2006; Furusho et al., 2009). This raised the possibility that FGF5 could be an autocrine regulator of Schwann cell behavior during nerve regeneration (McGeachie et al., 2001; Scarlato et al., 2001), however, the effects of FGF5 upon Schwann cells have not been examined.

In this report, we first systematically examined the expression of FGF5 and FGFR1-4 expression in Schwann cells upon injury, and then tested the effects of FGF5 on cultured primary rat Schwann cells. We show that FGF5 ligand is strongly up-regulated in mouse Schwann cells following injury, and FGFR1 and FGFR2 are highly expressed in Schwann cells of the mouse distal sciatic nerve. Using cultured primary rat Schwann cells, we show that FGF5 treatment rapidly promotes Schwann cell migration and adhesion via the upregulation of $\mathrm{N}$-cadherin, identifying an autocrine function for FGF5 upon Schwann cells that regulates Schwann cell migration and adhesion.

\section{MATERIALS AND METHODS}

\section{Animals and Peripheral Nerve Surgery}

All work involving animals was carried out according to Home Office regulation under the UK Animals Scientific Procedures Act 1986. Ethical approval for all experiments was granted by Plymouth University Animal Welfare and Ethical Review Board. Sprague-Dawley rats and C57BL/6 mouse breeding pairs were purchased from Charles River UK limited. PLP-GFP mice were described before Mallon et al. (2002) and Dun et al. (2019). All animals were housed in a controlled laboratory environment (temperature $22 \pm 2{ }^{\circ} \mathrm{C}$, humidity 50-60\%, 12-h light/dark cycle). All animals were fed with standard rodent diet and water added ad libitum. Two-month-old male and female mice were randomized and anesthetized with isoflurane, the right sciatic nerve was exposed and transected at approximately $0.5 \mathrm{~cm}$ proximal to the nerve trifurcation site and no re-anastomosis of the severed nerve was performed. The overlying muscle was sutured and the skin was closed with an Autoclip applier. All animals undergoing surgery were given appropriate post-operative analgesia, $0.05 \%$ bupivacaine solution, topically applied above the muscle suture before applying surgical clips. Meloxicam $(5 \mathrm{mg} / \mathrm{kg}$ ) injection was given just before recovery from anesthetic. All animals undergoing surgery were given nesting material and cage enrichment to minimize the risk of autotomy and monitored daily. At the indicated time points post-surgery for each experiment described, animals were euthanized humanely using carbon dioxide following UK Home Office regulations.

\section{FGF5, Primary and Secondary Antibodies}

Recombinant Human FGF5 (R\&D, 237-F5), anti-FGF5 antibody (Abcam, ab88118), anti-FGFR1 antibody (Abcam, ab10646), anti-FGFR2 antibody (Abcam, ab10648), CD206 antibody (R\&D, AF2535), Phospho-ERK1/2 antibody (Cell Signaling, \#9101), Total-ERK1/2 antibody (Cell Signaling, \#9102), N-cadherin (Becton-Dickinson, 610920) and GAPDH antibody (EMD Millipore, MAB374) were used. Hoechst and speciesspecific secondary antibodies conjugated with Alexa Fluor 488 or 568 dyes were purchased from Invitrogen. Horseradish peroxidase (HRP) conjugated secondary antibodies for western blotting were purchased from Sigma.

\section{mRNA Purification, cDNA Synthesis, RT-PCR and QRT-PCR}

Total mRNA was extracted using a miRNeasy Mini Kit (Qiagen, 217004) and the first-strand cDNA was synthesized with M-MLV reverse transcriptase (Promega, M368) using random hexamer primers (Promega, C1181). RT-PCR was performed in the G-Storm GS4M, qRT-PCR was performed in the PCR LightCycler480 Real-Time PCR Instrument (Roche Applied Science) using SYBR Green I Master with the primers showing in Table 1. Crosspoint (Cp) values were calculated by using the software of the LightCycler480 Real-Time PCR Instrument. 
TABLE 1 | Sequence information of forward and reverse primers.

\begin{tabular}{|c|c|c|c|}
\hline Primers & Forward: $5^{\prime}-3^{\prime}$ & Reverse: $5^{\prime}-3^{\prime}$ & Size \\
\hline FGF5 & CCCACGAAGCCAGTGTGTTA & ATCGCGGACGCATAGGTATT & $199 \mathrm{bp}$ \\
\hline FGFR1 & GACTCTGGCCTCTACGCTTG & TGGGGATGTCCAGTAGGGAG & $194 \mathrm{bp}$ \\
\hline FGFR2 & CACGACCAAGAAGCCAGACT & CTCGGCCGAAACTGTTACCT & $94 \mathrm{bp}$ \\
\hline FGFR4 & GGAAGGTGGTCAGTGGGAAGT & CTGCTCCAGGATTGGGGCTA & $164 \mathrm{bp}$ \\
\hline GAPDH & AAGGTCATCCCAGAGCTGAA & СТGСТTCACСАCСТTCTTGA & $222 \mathrm{bp}$ \\
\hline
\end{tabular}

Relative mRNA levels were calculated by the 2(-Delta Delta $\mathrm{C}(\mathrm{T})$ ) method (Livak and Schmittgen, 2001) using GAPDH as a reference gene for normalization. All reactions were carried out in triplicate for statistical analysis.

\section{Schwann Cell Culture and FGF5 Treatment}

Schwann cells were prepared from the sciatic nerve and brachial plexus of day three Sprague-Dawley rats as previously described (Brockes et al., 1979; Dong et al., 1997; Maurel, 2018). Schwann cells were cultured in six well plates with low glucose $(1 \mathrm{~g} / \mathrm{ml})$ DMEM containing 10\% fetal bovine serum (FBS), $10 \mathrm{ng} / \mathrm{ml}$ NRG-1 (R\&D, Cat No. 396-HB-050) and $2 \mu \mathrm{M}$ forskolin (Sigma, Cat No. 344270). For the ERK activation experiment, Schwann cells were starved in low glucose DMEM containing $1 \%$ FBS overnight. The following morning cells were treated with $10 \mathrm{ng} / \mathrm{ml} \mathrm{FGF5}$ and lysed after 0, 5, 10, 20, 30, and 60 min of treatment. For extended FGF5 treatment, Schwann cells were changed to low glucose DMEM containing 10\% FBS $16 \mathrm{~h}$ before FGF5 treatment, and the following morning treated with $5 \mathrm{ng} / \mathrm{ml} \mathrm{FGF5}$ and images were taken every $2 \mathrm{~h}$ on a LeicaIM8 microscope.

\section{Immunohistochemistry and Immunocytochemistry}

Sciatic nerve samples were dissected out and fixed overnight in $4 \%$ paraformaldehyde (in PBS, PH7.2) at $4^{\circ} \mathrm{C}$. The samples were then washed in PBS $(3 \times 10 \mathrm{~min})$ and dehydrated in $30 \%$ sucrose (in PBS) overnight at $4^{\circ} \mathrm{C}$. Subsequently, samples were embedded in OCT medium and sectioned on a cryostat at a thickness of $12 \mu \mathrm{m}$. Schwann cells cultured on coverslips were fixed in $4 \%$ paraformaldehyde at $4^{\circ} \mathrm{C}$ for $15 \mathrm{~min}$ and then washed in PBS $(3 \times 10 \mathrm{~min})$. The sections or cells were permeabilized with $0.25 \%$ Triton $\mathrm{X}-100$ plus $1 \%$ bovine serum albumin (BSA) in PBS for $45 \mathrm{~min}$ and then blocked with blocking buffer (3\% BSA plus $0.05 \%$ Triton $\mathrm{X}-100$ in PBS) for $1 \mathrm{~h}$ at room temperature. The sections or cells were incubated with primary antibodies (1:100 diluted in blocking buffer) overnight at $4^{\circ} \mathrm{C}$. The next day, sections were washed with PBS $(3 \times 10 \mathrm{~min})$ and then incubated with species-specific secondary antibodies plus Hoechst dye (1:500 diluted in blocking buffer) for $1 \mathrm{~h}$ at room temperature. Finally, sections were washed with PBS $(3 \times 10 \mathrm{~min})$ and mounted with Citifluor (Agar Scientific, R1320) for imaging with a Leica SPE confocal microscope (Dun et al., 2019).

\section{Western Blot}

Nerve samples were dissected out with similar size and directly sonicated into $1 \times$ SDS loading buffer. Cells were lysed in $200 \mu \mathrm{l}$ of radio-immunoprecipitation assay (RIPA) buffer (50 mM
Tris- $\mathrm{HCl}, \mathrm{pH} \quad 7.4,0.1 \%$ SDS, $1 \%$ NP-40, $150 \mathrm{mM} \mathrm{NaCl}$, $1 \mathrm{mM}$ ethylenediaminetetraacetic acid (EDTA), 0.5\% sodium deoxycholate) plus phosphatase inhibitor cocktails (1:100, Santa Cruz Biotechnology, sc-45045 and sc-45065). Cell lysates were spun down at $16,000 \times g$ for $15 \mathrm{~min}$ at $4^{\circ} \mathrm{C}$. The supernatant was transferred to new $1.5 \mathrm{ml}$ microcentrifuge tubes and the protein concentration was determined using the Pierce ${ }^{\mathrm{TM}} \mathrm{BCA}$ Protein Assay Kit. An appropriate volume of samples containing $20 \mu \mathrm{g}$ of protein was added to the $4 \times$ sample buffer. Proteins were separated on $10 \%$ or $12 \%$ SDS polyacrylamide running gels and transferred onto a polyvinylidene fluoride (PVDF, $0.45 \mu \mathrm{m})$ transfer membrane using the wet transfer method. Membranes were blocked in 5\% fat-free milk in TBST (Trisbuffered saline plus $0.1 \%$ Tween-20) for $1 \mathrm{~h}$ at room temperature. Primary antibodies were diluted (1:500) in 5\% milk (in TBST) and the membranes were incubated in primary antibodies overnight at $4^{\circ} \mathrm{C}$. The next day, membranes were washed in TBST $(3 \times 10 \mathrm{~min})$ and then incubated with HRP conjugated secondary antibody (Sigma, 1:5,000 in 5\% milk, TBST) for $1 \mathrm{~h}$ at room temperature. After three TBST washes (10 min each), Pierce ECL western blotting substrate was added onto the membrane and incubated for $5 \mathrm{~min}$ to develop the chemiluminescent signal. Amersham Hyperfilm ${ }^{\mathrm{TM}}$ ECL films were used to capture the intensity of the chemiluminescent signal. Exposed films were then developed in a Compact X4 automatic processor. The intensity of protein bands was quantified using the free Image software available from https://imagej.nih.gov/ij/.

\section{Cell Viability Assay}

Culturing medium in the 6-well plate was carefully removed and Schwann cells were washed once with $1 \mathrm{ml}$ PBS. Schwann cells were then stained with a $1.5 \mathrm{ml}$ trypan blue solution (0.4\%, Thermo Fisher Scientific, Cat No.:15250061; Strober, 2015; Lebeau et al., 2019). After 2 min staining, cells were rinsed twice with $1 \mathrm{ml}$ PBS and a final $1.5 \mathrm{ml}$ PBS was added into the wells for immediately imaging using a LeicaIM8 microscope.

\section{Statistical Analysis}

The samples for Western blotting and qRT-PCR were prepared by grouping three nerves from three different mice together for each time point to create a pooled sample as $n=1$, and then repeated the process using another six animals to reach $n=3$. Therefore, we have used pooled biological replicates for the repetition of these experiments. Statistical significance was analyzed using the Student's $t$-test by comparing the test groups with the control groups. Data are represented in the figures as mean value \pm SEM. 


\section{RESULTS}

\section{Analysis of FGF5 Up-Regulation in Schwann Cells and in the Mouse Distal Sciatic Nerve With Published Microarray and mRNA Sequencing Data Sets}

Previously, we studied the gene expression profile of cultured rat primary Schwann cells by microarray analysis (Dun et al., 2019). Analyzing the expression of all FGF family members in our microarray data (GSE123915) showed that FGF5 has the highest expression level in cultured rat primary Schwann cells (Figure 1A). Recently, Clements et al. (2017) studied in vivo Schwann cell mRNA expression by an mRNA sequencing technique with Schwann cells isolated from intact and 7 days injured mouse sciatic nerve (GSE103039). Analyzing their mRNA sequencing data showed that FGF5 mRNA is up-regulated greater than 50-fold in Schwann cells following injury (Figure 1B). We further analyzed two published microarray data sets, GSE22291 and GSE74087, in the Gene Expression Omnibus $\left(\mathrm{GEO}^{1}\right)$ that have studied the time course of gene expression in adult mouse distal sciatic nerve at 3, 7 and 14 days post-injury (Barrette et al., 2010; Pan et al., 2016). Although FGF5 fold changes have large differences between two data sets of GSE22291 and GSE74087, analyzing both data sets showed that FGF5 is highly up-regulated in the mouse distal sciatic nerve at 3, 7 and 14 days following injury (Figures 1C,D).

\section{Validation of FGF5 Increase in Schwann Cells of the Mouse Distal Sciatic Nerve Following Injury}

Next, we validated FGF5 mRNA up-regulation in mouse distal sciatic nerve following injury. RT-PCR results showed weak FGF5 expression on intact adult mouse sciatic nerve with an upregulation in the distal sciatic nerve at 7 days following injury (Figure 2A). Quantitative PCR showed that FGF5 was significantly up-regulated from day 4 to day 14 in the mouse distal sciatic nerve compared to intact control contralateral nerve (Figure 2D). On day 4 after injury, FGF5 mRNA showed an almost 90-fold up-regulation compared to uninjured controls, with an even higher increase seen $(>300)$ at 7 days and with a greatly increased expression at days 10 and 14 (Figure 2D). The FGF5 mRNA fold changes from our qPCR data show high similarity with the microarray data set GSE74087 (Figure 1D). Consistent with the results of the FGF5 mRNA expression pattern, FGF5 protein measurement by Western blotting is low in the intact mouse sciatic nerve and is highly up-regulated in the distal sciatic nerve following injury (Figures 2B,C). Our western blot results also showed that cultured rat primary Schwann cells express high levels of FGF5 protein (Figures 2B,C). Staining FGF5 on cultured rat primary Schwann cells revealed that FGF5 shows a punctate expression pattern in Schwann cell cytoplasm (Figure 2E), a typical staining pattern for secreted polypeptides (van Lieshout et al., 1995; Whim and Moss, 2001).

\footnotetext{
${ }^{1}$ http://www.ncbi.nlm.nih.gov/geo/
}

To confirm the expression of FGF5 in Schwann cells of the sciatic nerve, we stained FGF5 on intact and injured sciatic nerve sections from PLP-GFP mice, which label Schwann cells GFP-positive (Mallon et al., 2002; Carr et al., 2017; Dun et al., 2019). Staining of FGF5 on intact sciatic nerve transverse sections from PLP-GFP mice showed that FGF5 could be easily detected in the cell bodies of myelinating Schwann cells (Figures 3A-D, indicated by white arrows). Staining for FGF5 on injured nerves of PLP-GFP mice at 7 days post-injury revealed that Schwann cells are the principal cells expressing FGF5 (Figures 3E-H, indicated by white arrows). Previously, McGeachie et al. (2001) found that macrophages in skeletal muscle also express FGF5 after denervation. Resident and infiltrated macrophages are an important cell type in the distal nerve promoting peripheral nerve regeneration following injury and comprise $20 \%$ of cells in the distal sciatic nerve (Stierli et al., 2018). Ydens et al. (2012) showed that the majority of macrophages in the distal nerve show an M2 phenotype. Therefore, we double stained FGF5 with an M2 macrophage marker CD206 on distal sciatic nerve longitudinal sections from C57BL/6 mice at 7 days post-injury. Our staining showed that FGF5 is not expressed in M2 macrophages of the distal sciatic nerve (Figures 3I-L, indicated by white arrows).

\section{FGF5 Receptors Expression in Schwann Cells of the Mouse Distal Sciatic Nerve Following Injury}

The FGF family molecules can bind to FGFR1-4 and regulate migration, proliferation, differentiation, survival, and metabolic activities in a wide variety of cells (Ornitz and Itoh, 2015). To understand the role of FGF5 in Schwann cells during peripheral nerve regeneration, we used RT-PCR to detect FGFR1-4 expression in intact mouse sciatic nerve, and in the distal sciatic nerve following injury. Results showed that FGFR1-3 mRNAs are present in the intact and injured mouse sciatic nerve but FGFR4 is hardly detectable both before and after injury (Figure 4A). FGFR1 appears at the highest level of expression in the mouse sciatic nerve both before and after injury. FGFR2 is also expressed, but the expression of FGFR3 is very weak (Figure 4A). We next analyzed FGFR1-4 mRNA expression in Schwann cells isolated from intact and 7 days injured mouse sciatic nerve with the data set of GSE103039 (Clements et al., 2017). Consistent with our RT-PCR results, FGFR1-3 mRNA could be detected in isolated Schwann cells by mRNA sequencing both before and after injury but FGFR4 mRNA was undetectable (Clements et al., 2017). Analyzing the mRNA sequencing data of the Clements dataset also showed that Schwann cells in the mouse distal sciatic nerve express the highest levels of FGFR1, followed by FGFR2 and then FGFR3 (Figures 4B,C). We also analyzed FGFR1-3 expression on cultured rat primary Schwann cells with our microarray data set GSE123915 (Dun et al., 2019). In agreement with the mRNA sequencing data of FGFR1-3 expression levels in vivo for Schwann cells, relative expression levels of FGFR1>FGFR2>FGFR3 were observed (Figure 4D). 

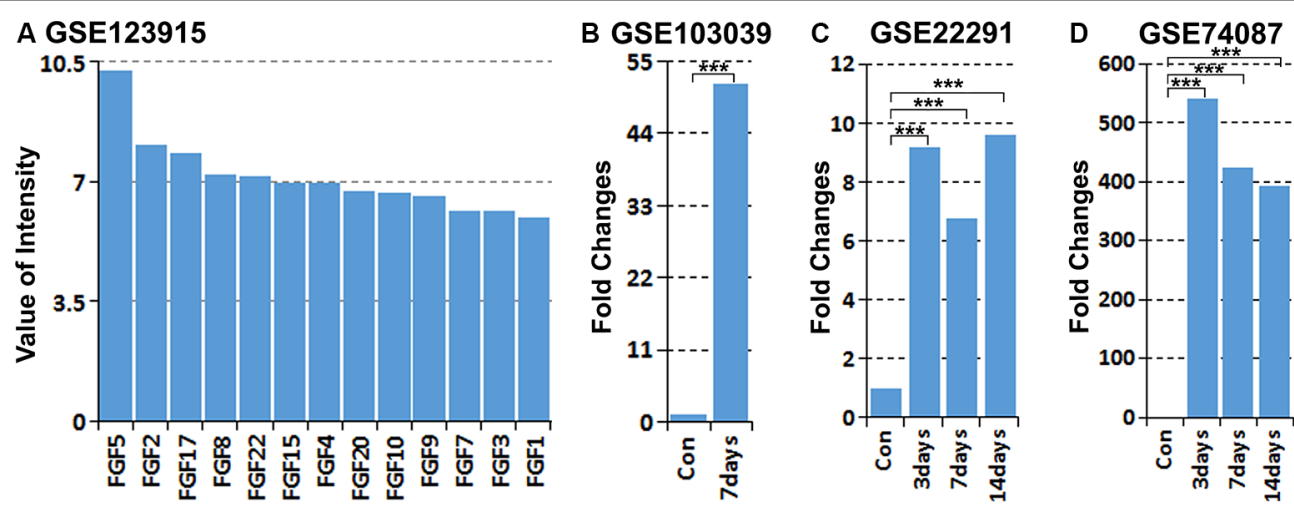

FIGURE 1 | Analysis of fibroblast growth factor 5 (FGF5) up-regulation in Schwann cells and in the mouse distal sciatic nerve from published microarray and mRNA sequencing data sets. (A) Analyzing the expression of all FGFs in cultured rat primary Schwann cells with our microarray data GSE123915, FGF5 has the highest expression level in cultured rat primary Schwann cells. (B) Analyzing FGF5 mRNA up-regulation in Schwann cells of the distal mouse sciatic nerve 7 days post-injury with the mRNA sequencing data set GSE103039, FGF5 mRNA level is 51.5-fold upregulated in Schwann cells compared to the uninjured nerve. (C,D) Analyzing microarray data sets GSE22291 and GSE74087 showing FGF5 mRNA up-regulation in the mouse distal sciatic nerve at 3, 7, and 14 days post-injury.

${ }^{* * *}$ Indicates $p<0.001$
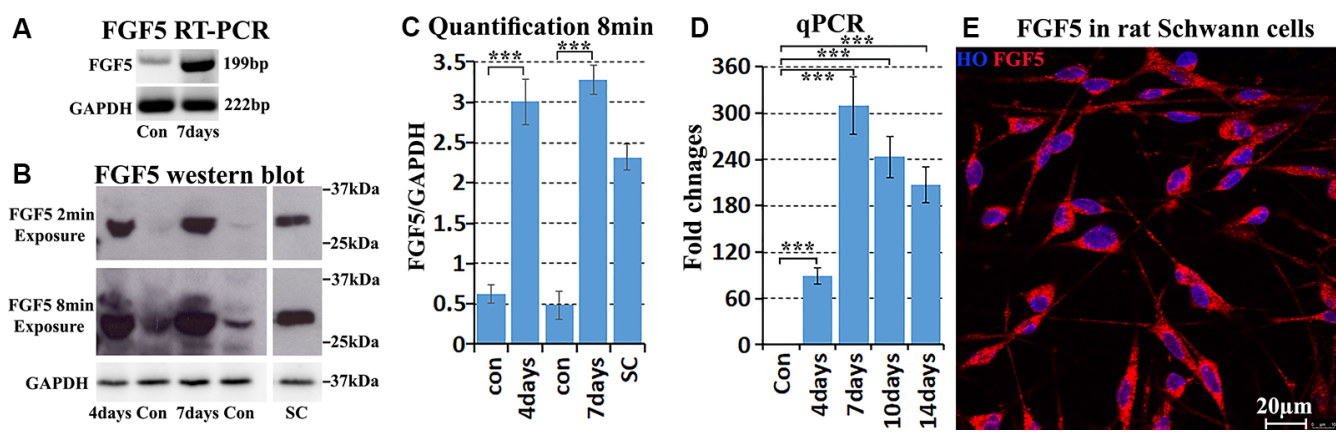

FIGURE 2 | Validation of FGF5 up-regulation in mouse distal sciatic nerve and cultured Schwann cells. (A) RT-PCR showing weak FGF5 mRNA expression in control sciatic nerve and strong expression in the distal sciatic nerve at 7 days post-injury. (B) Western blot detecting weak FGF5 protein expression in control mouse sciatic nerve and strong up-regulation in distal sciatic nerve at 4 and 7 days post-injury. Cultured rat primary Schwann cells express a high level of FGF5 protein. (C) Quantification of three independent FGF5 western blot results. (D) Quantitative PCR validates FGF5 mRNA up-regulation in the mouse distal sciatic nerve at 4, 7 , 10, and 14 days post-injury; intact contralateral sciatic nerves used as control samples. (E) Staining of FGF5 on cultured rat primary Schwann cells shows punctate FGF5 expression pattern in Schwann cell cytoplasm. HO: Hoechst. Scale bar in (E) $20 \mu \mathrm{m} .{ }^{\star \star *}$ Indicates $p<0.001$.

Next, we immunolabeled for FGFR1 and FGFR2 on intact and injured sciatic nerve sections from PLP-GFP mice. Staining for FGFR1 and FGFR2 on intact sciatic nerve transverse sections showed that FGFR1 and FGFR2 are both primarily expressed on Schwann cells of the sciatic nerve (Figure 5). Staining of FGFR1 and FGFR2 on distal sciatic nerve transverse sections from PLP-GFP mice at 7 days post-injury revealed that Schwann cells are the principal cells expressing FGFR1 (Figures 5E-H) and FGFR2 (Figures 5M-P) in the distal sciatic nerve.

\section{FGF5 Regulates Schwann Cell Migration and Adhesion}

Initially, FGF5 was suggested to have a function in promoting the survival of motoneurons (Hughes et al., 1993), although a loss of motoneurons in go mutation homozygous mice was not observed (McGeachie et al., 2001). A regeneration defect of motor axon reinnervation was also not observed in go mutation homozygous mice (Moscoso et al., 1998). Based on the expression of FGFR1 and FGFR2 on Schwann cells, FGF5 has been suggested as an autocrine regulator for Schwann cell proliferation and survival during Wallerian degeneration (McGeachie et al., 2001; Scarlato et al., 2001), but this possible FGF5 function remains to be examined. FGF-mediated cell proliferation and survival are primarily triggered by the activation of downstream mitogen-activated protein kinase (MAPK) signaling pathways (Ornitz and Itoh, 2015; Tian et al., 2019). Therefore, we treated cultured rat primary Schwann cells with FGF5 and examined ERK1/2 activation by western blot. To our surprise, FGF5 treatment failed to activate ERK1/2 in Schwann cells but instead inhibited the basal level of ERK1/2 activity (Figures 4E,G).

Having not observed ERK1/2 activation in Schwann cells up to $1 \mathrm{~h}$ following FGF5 treatment, we extended the time 


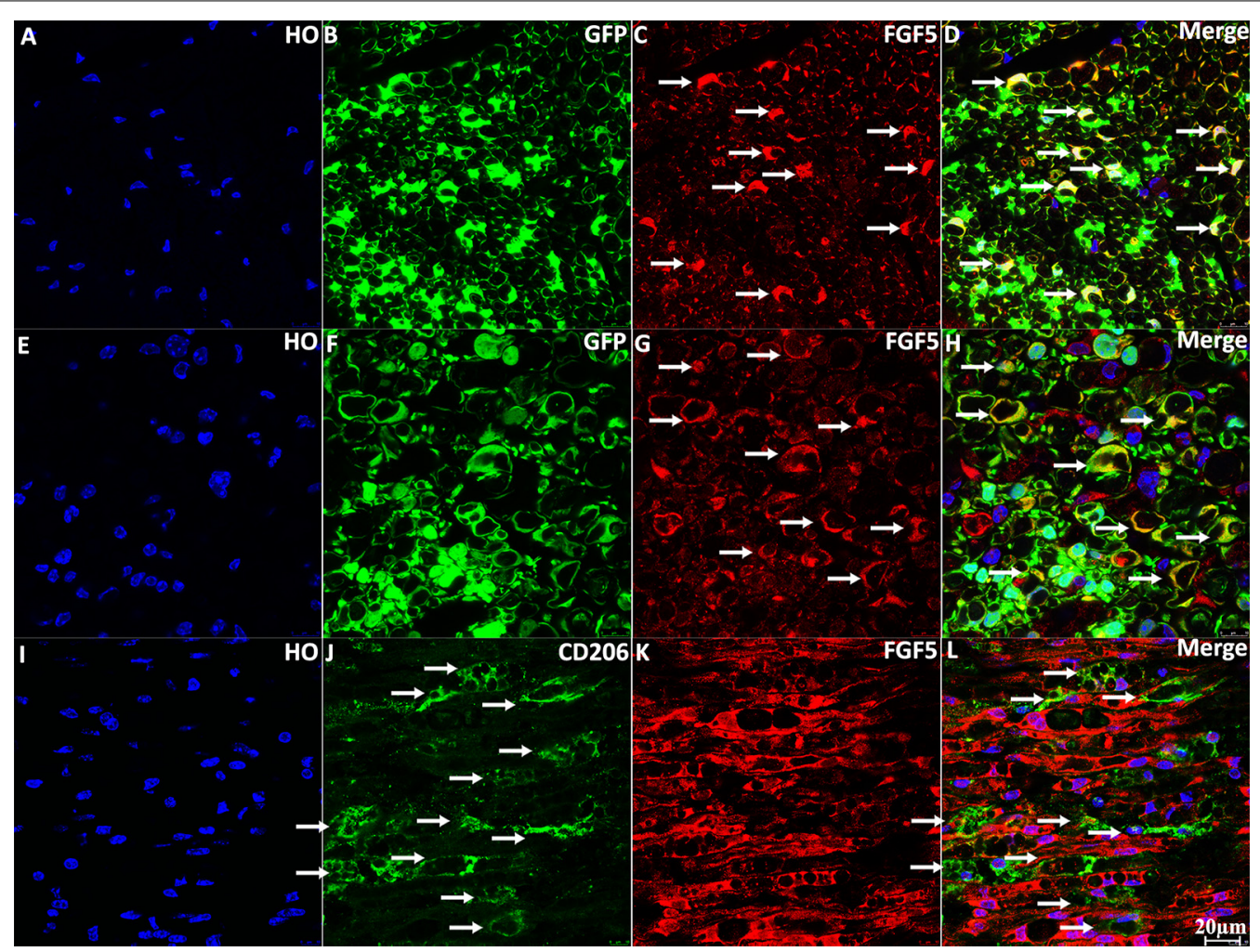

FIGURE 3 | Staining of FGF5 in intact and 7 days post-injury mouse sciatic nerve. (A-D) Staining of FGF5 on intact sciatic nerve transverse sections from PLP-GFP mice. FGF5 can be seen in the cell bodies of myelinating Schwann cells (indicated by arrows in panel C). (E-H) Staining of FGF5 on distal sciatic nerve transverse sections from PLP-GFP mice at 7 days post-injury; Schwann cells are the principal cells expressing FGF5 in the distal sciatic nerve. (I-L) Double staining of FGF5 with the macrophage marker CD206 on longitudinal sections of the distal sciatic nerve from C57BL/6 mice at 7 days post-injury; FGF5 is not expressed in macrophages of the distal sciatic nerve. HO: Hoechst. Scale bar $20 \mu \mathrm{m}$.

of FGF5 treatment to examine FGF5 effects on Schwann cells. Interestingly, we observed rapid Schwann cell movement after $2 \mathrm{~h}$ of treatment and increased cell-cell adherence (Figure 6B). Following FGF5 treatment, Schwann cells could be observed moving toward each other and forming distinct clusters, in a time-dependent manner with Schwann cell processes connecting adjacent clusters (Figure 6). The Schwann cell cluster formation indicated that FGF5 not only regulates rapid Schwann cell movement but also strongly enhances Schwann cell adhesion. At $6 \mathrm{~h}$ of treatment, lager Schwann cell clusters could be observed and more larger space appeared in the wells of six-well plates, Schwann cells within the same cluster could be observed growing on top of each other. At this stage, some individual Schwann cells could be seen but they are sending a long process connecting with surrounding clusters (Figure 6D). By the time of $8 \mathrm{~h}$ of treatment, small clusters have moved toward each other and formed even larger clusters. The Schwann cell processes connecting different clusters still could be seen, but it is rare to see individual Schwann cells in space (Figure 6E). It appears that the connecting processes could communicate between cells and promote adjacent clusters moving together to form larger clusters. At $10 \mathrm{~h}$ of treatment, all the clusters moved together and formed three or four big clusters in each well of the six-well plate (Figure 6F). We further performed trypan blue exclusion staining to test the cell viability because most cell clusters detached from the wells after $10 \mathrm{~h}$ of FGF5 treatment. The staining showed that Schwann cells are alive although they formed clusters and detached from the wells (Figures 6G-I).

Previous studies showed that N-cadherin is upregulated in Schwann cells following peripheral nerve injury and N-cadherin is a key adhesion molecule that regulates Schwann cell migration and adhesion (Wanner and Wood, 2002; Parrinello et al., 2010; Clements et al., 2017; Roberts et al., 2017). We then examined $\mathrm{N}$-cadherin expression in Schwann cells by western blot following FGF5 treatment. The western blot results revealed that $\mathrm{N}$-cadherin expression is significantly upregulated in Schwann cells after 4, 6, 8, and 10 h of FGF5 treatment (Figures $4 \mathbf{F}, \mathbf{H}$ ). Thus, we identified an FGF5 autocrine function regulating Schwann cell migration and adhesion via the upregulation of $\mathrm{N}$-cadherin.

\section{DISCUSSION}

The FGF family consists of 22 structurally related molecules that bind with high affinity to four FGF receptors (FGFR1-4). Activation of FGF-FGFR signaling and subsequent biological activities not only depend on the spatial and temporal expression 


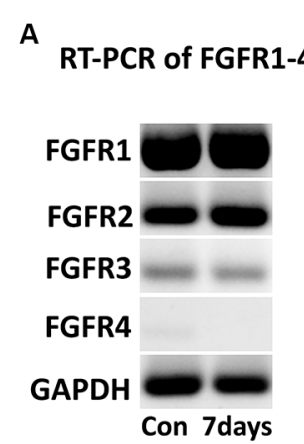

E

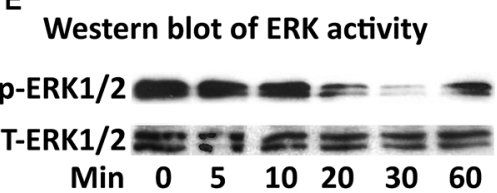

F Western blot of $\mathrm{N}$-Cadherin

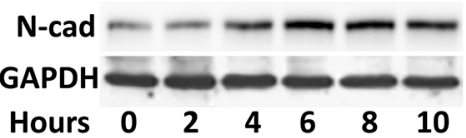

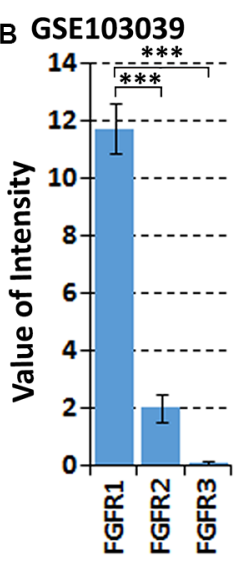

G
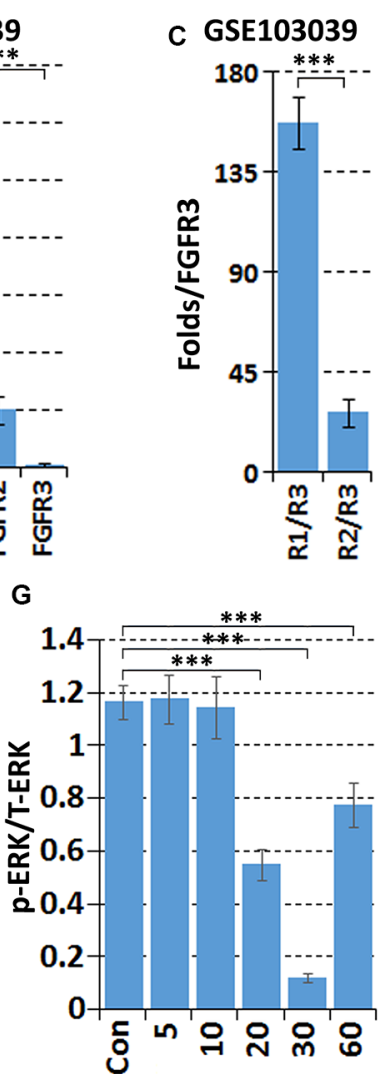

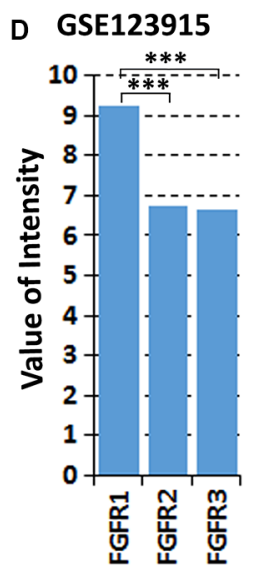

$\mathrm{H}$

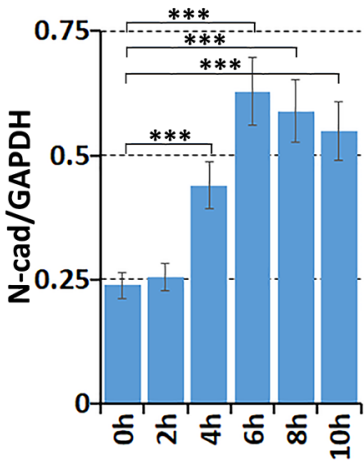

FIGURE 4 | Expression of FGFR1-4 in intact and injured mouse sciatic nerve. (A) RT-PCR showing FGFR1-4 mRNA expression in control and 7 days post-injury mouse sciatic nerve. (B) Data showing expression of FGFR1-3 mRNA at 7 days post-injury from mRNA sequencing data set GSE103039. (C) Fold difference of FGFR1 and FGFR2 against FGFR3 analyzed with the mRNA sequencing data set GSE103039. (D) The expression value of FGFR1-3 in cultured Schwann cells in our microarray data set GSE123915. (E) Western blot results showing that FGF5 inhibits the basal levels of ERK1/2 activity in cultured rat primary Schwann cells. (F) Western blot results showing that FGF5 significantly upregulates N-cadherin expression in Schwann cells after 4, 6, 8, and 10 h treatment. (G) Quantification of three independent western blot results for ERK1/2 inhibition by FGF5. (H) Quantification of three independent western blot results for N-cadherin upregulation. ${ }^{* * *}$ Indicates $p<0.001$.

pattern of FGFs but also the expression patterns of the FGFR14 receptors (Ornitz and Itoh, 2015; Tian et al., 2019). Numerous recent studies have reported roles for the FGFs in tissue and organ regeneration, such as FGF2, FGF4, and FGF8 for the limb/digit regeneration, FGF1 and FGF8 for lens regeneration, FGF2 for nervous system regeneration and FGF7 for skin and intestinal regeneration (Nunes et al., 2016; Maddaluno et al., 2017). Among all the FGFs, FGF1 and FGF2 have been studied in peripheral nerve regeneration. FGF1 expression is restricted largely to neurons, therefore levels of FGF1 protein fall in the distal nerve following injury and axon degradation (Eckenstein et al., 1991; Ishikawa et al., 1992). FGF-2, in contrast, is expressed by Schwann cells both before and after peripheral nerve injury (Meisinger and Grothe, 1997; Grothe et al., 2006; Furusho et al., 2009). Overexpression of FGF2 promoted peripheral nerve regeneration and increased Schwann cell proliferation, axonal regrowth, and re-myelination (Jungnickel et al., 2006). Additionally, repairing of a nerve gap following transection with a silicone tube containing FGF2 overexpressing Schwann cells also promoted peripheral nerve regeneration (Allodi et al., 2014).
So far, the best-established biological effect of FGF5 is as a paracrine inhibitor of proliferation of hair outer root sheath cells (Pethö-Schramm et al., 1996; Higgins et al., 2014). In humans, FGF5 is expressed within the upper outer root sheath cells of hair follicles, with FGF5 mutation resulting in excessively long eyelashes (Higgins et al., 2014). Global FGF5 knockout mice are viable and have an abnormally long hair phenotype, which is also seen in many other mammalian species (Hébert et al., 1994). This phenotype is identical to that of mice homozygous for the spontaneous mutation angora (go) mice. FGF5 knockout mice and go mutations crossbreeding failed to rescue each other's long hair phenotype, resulting in the identification of exon 1 deletion of FGF5 DNA in go mutant mice. Thus, go is a mutant allele of FGF5 (Hébert et al., 1994). The long hair phenotype has also been reported in other species. Genome-wide association studies in dogs identified a mutation in FGF5 that is associated with hair length (Housley and Venta, 2006; Dierks et al., 2013). A missense mutation in FGF5 was found in longhaired cats (Drögemüller et al., 2007; Kehler et al., 2007). The long-hair phenotype of FGF5 gene knockout or mutations has also been 


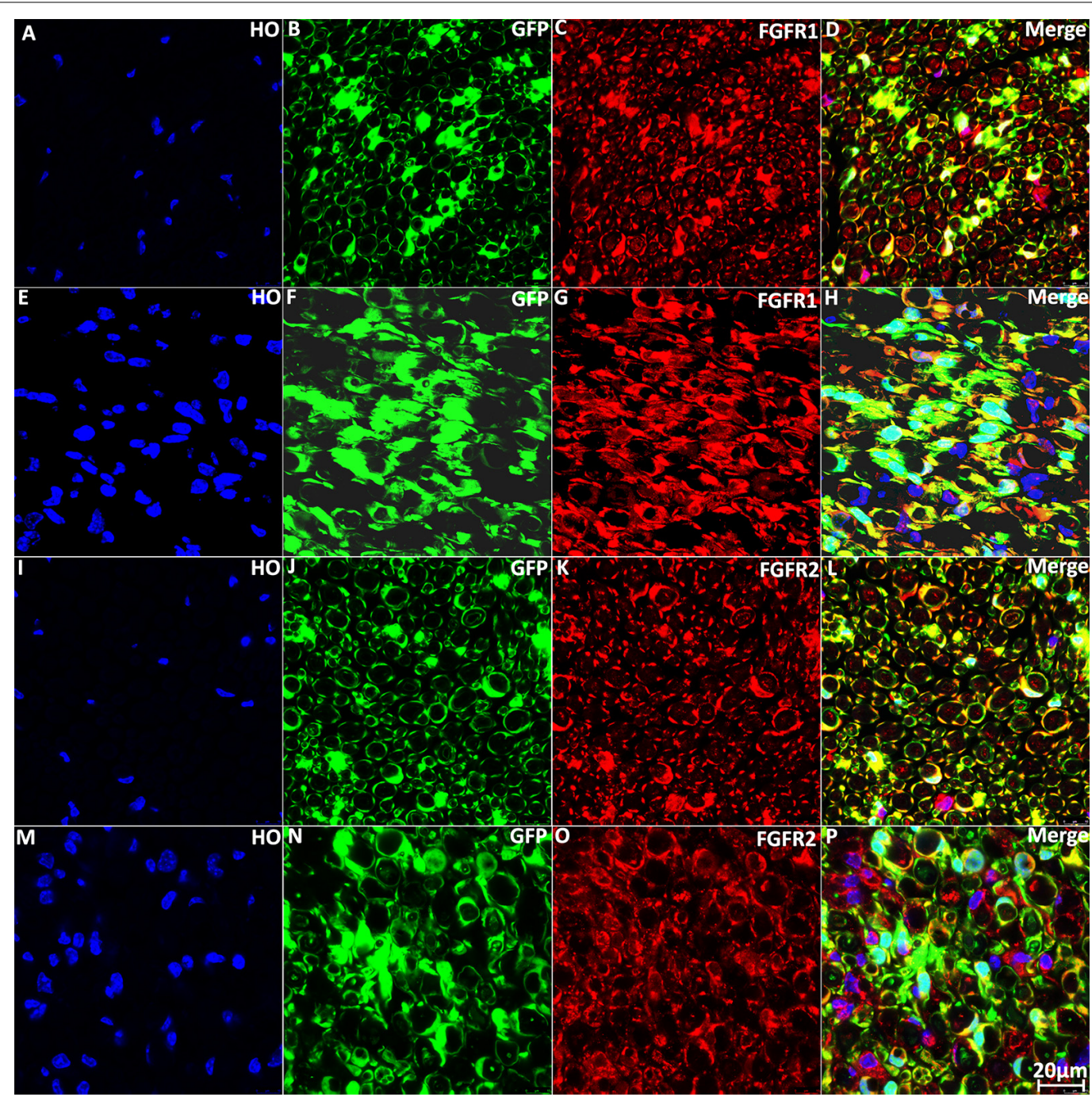

FIGURE 5 | Staining of FGFR1 and FGFR2 in intact and injured mouse sciatic nerve of PLP-GFP mice. (A-D) Staining of FGFR1 on intact sciatic nerve transverse sections from PLP-GFP mice. (E-H) Staining of FGFR1 on distal sciatic nerve transverse sections from PLP-GFP mice at 7 days post-injury; Schwann cells are the principal cells expressing FGFR1 in the distal sciatic nerve. (I-L) Staining of FGFR2 on intact sciatic nerve transverse sections from PLP-GFP mice. (M-P) Staining of FGFR2 on distal sciatic nerve transverse sections from PLP-GFP mice at 7 days post-injury, Schwann cells in the distal sciatic nerve express FGFR2. HO: Hoechst. Scale bar $20 \mu \mathrm{m}$.

reported in sheep, goat, donkey, hamster and guinea pigs (Legrand et al., 2014; Wang et al., 2015, 2016; Yoshizawa et al., 2015, 2016; Hu et al., 2017; Li et al., 2017; Yu et al., 2018). These findings provide evidence that FGF5 functions as an inhibitor of hair elongation, thus identifying one of the FGF5 key functions.

Northern blot analysis of total RNA obtained from hindlimb skeletal muscle of embryonic, postnatal and adult rats showed that FGF5 mRNA is expressed in rat skeletal muscle during the period of embryonic motoneuron death as well as in the adult skeletal muscle (Hughes et al., 1993). Therefore, the potential role of FGF5 functioning as a target-derived trophic factor for spinal motoneurons has been examined in vitro. In vitro experiments showed that recombinant FGF5 promoted the survival of cultured embryonic chick motoneurons. Extracts from rat skeletal muscle also promoted the survival of cultured embryonic chick motoneurons and the motoneuron survival activity of rat skeletal muscle extracts could be immunoprecipitated using an antiserum to FGF5 (Hughes et al., 1993). Lindholm et al. (1994) also reported that FGF5 has neurotrophic activity on cultured rat septal cholinergic and raphe serotonergic neurons. Above in vitro results suggested that FGF5 might act as a target-derived trophic factor for motoneurons. However, in vivo studies using the double-ligation technique has revealed that endogenous FGF5 is not transported in motor axons. Furthermore, stereological estimates of the number of motoneurons in go homozygotes mice failed to reveal any loss of any motoneurons compared to control mice (McGeachie et al., 2001). Moreover, another study also failed to discover any abnormalities of the motor nerve terminal Schwann 


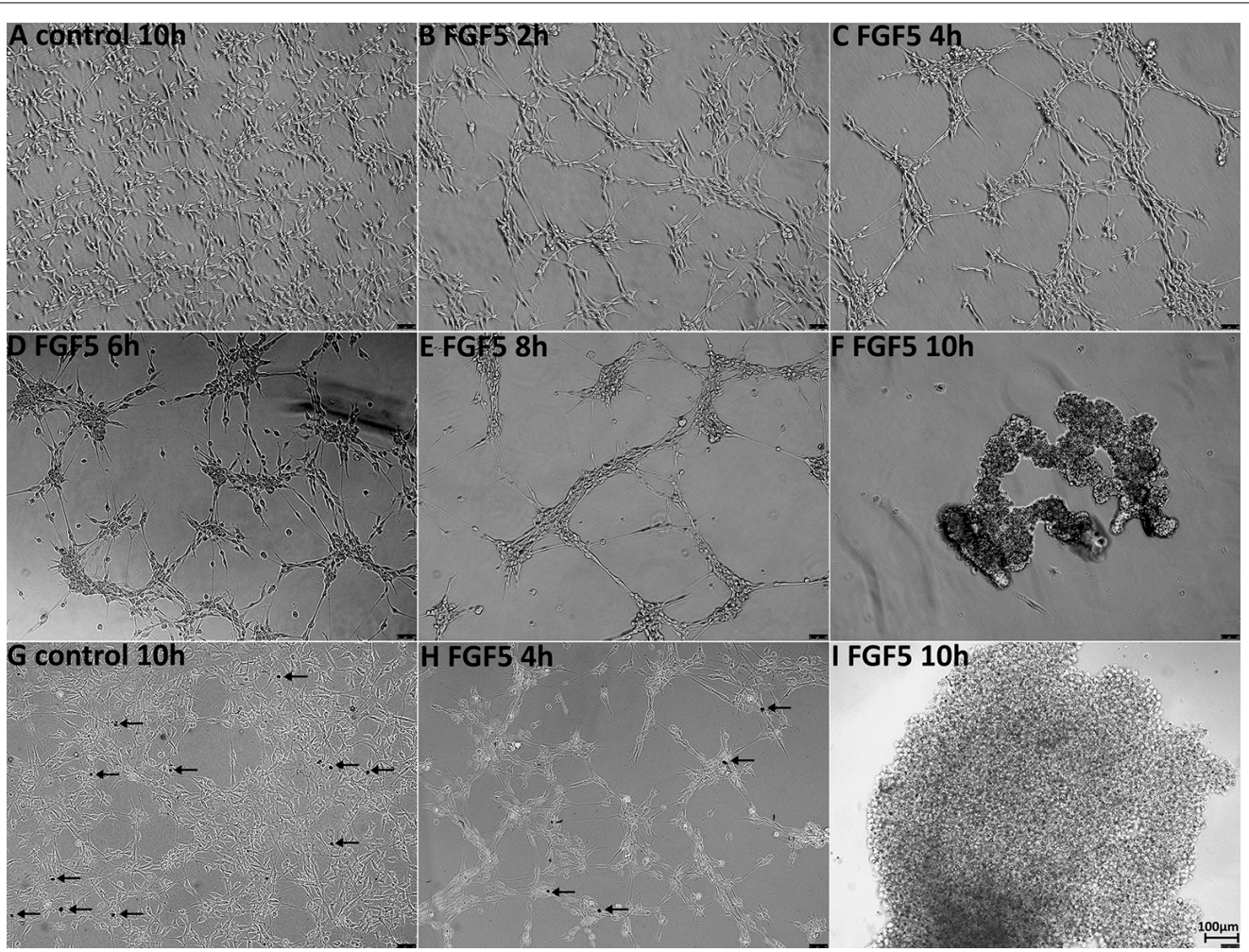

FIGURE 6 | FGF5 regulates Schwann cell migration and adhesion. (A) Phase-contrast image of control untreated rat primary Schwann cells. (B-F) Phase-contrast images of FGF5-treated (5 ng/ml) rat primary Schwann cells at timepoints 2, 4, 6, 8, and $10 \mathrm{~h}$. (G-I) Phase-contrast images show cell viability in control and FGF5-treated Schwann cells, stained by trypan blue. Arrows in panels $\mathbf{( G , H )}$ indicate dead cells. At 10 h of FGF5 treatment in panel $\mathbf{( I )}$, there were no dead cells stained by trypan blue in Schwann cell clusters. Scale bar $100 \mu \mathrm{m}$.

cells, synaptic basal lamina, or postsynaptic membrane in go homozygous mice (Moscoso et al., 1998). Taken together, these results demonstrated that FGF5 is dispensable for major aspects of the nervous system development.

While FGF5 is dispensable during nervous system development (Moscoso et al., 1998; McGeachie et al., 2001). McGeachie et al. (2001) showed that FGF5 mRNA was up-regulated 50-fold in denervated muscles at 7 days after denervation, and remained high for at least 28 days. They carefully examined the FGF5-positive cell types in rat skeletal muscles, showing that FGF5 mRNA and protein were expressed in both terminal and non-terminal Schwann cells of the skeletal muscles but not in muscle fibers (McGeachie et al., 2001). Scarlato et al. (2001) also reported that FGF5 is dramatically up-regulated in Schwann cells of the peripheral nerves following axotomy, but FGF5 levels gradually returned to normal upon the contact of regenerating axons with Schwann cells. Cultured Schwann cells express FGF5 and forskolin treatment elevates FGF5 expression in cultured Schwann cells. Their study provided evidence that axon-Schwann cell interaction regulates FGF5 levels in Schwann cell of the peripheral nerves as the time course of FGF5 level changes matches with the time course of axon degeneration and regeneration (Scarlato et al., 2001), although in vivo experiments in the go homozygous FGF5 mouse mutant failed to reveal any differences in the measured regeneration (Moscoso et al., 1998). Thus, an FGF5 function in peripheral nerve regeneration has not been identified with these studies.

Previously, Scarlato et al. (2001) reported that they could not detect FGF5 mRNA and protein in adult intact sciatic nerves. FGF5 is highly up-regulated following peripheral nerve injury, therefore, FGF5 has been named as one of the injury-induced genes (Ma et al., 2016). In contrast, McGeachie et al. (2001) demonstrated by RT-PCR that FGF5 mRNA is expressed in adult mouse sciatic nerve. In this study, we found that both FGF5 mRNA and protein could be detected in intact mouse sciatic nerve, and it is expressed by myelinating Schwann cells. Thus, FGF5 expression in the peripheral nerves is not purely induced by injury response.

The FGF-FGFR signaling pathways regulate important biological processes including cell proliferation and differentiation during development and tissue repair. Upon binding to their high-affinity receptors, FGFs activate various signaling cascades, of which the Ras-ERK1/2 signaling pathway is most prominent (Ornitz and Itoh, 2015). Recently, Tian et al. (2019) also reported that FGF5 promoted spermatogonial stem cell proliferation via ERK and AKT activation. Previous studies have suggested FGF5 as an autocrine regulator for Schwann cell proliferation and survival during Wallerian 
degeneration because Schwann cells in the distal nerve express FGFRs (Meisinger and Grothe, 1997; McGeachie et al., 2001; Scarlato et al., 2001; Grothe et al., 2006; Furusho et al., 2009). In this report, we showed that Schwann cells in the distal nerve express a high level of FGFR1 and FGFR2, and it has been reported that FGF5 could activate FGFR1 and FGFR2 with a Kd value of approximately $1 \mathrm{nM}$ (Clements et al., 1993). This raised the possibility that FGF5 could be an autocrine regulator of Schwann cell proliferation following peripheral nerve injury. However, our FGF5 treatment inhibited the basal level of ERK1/2 activity in cultured rat primary Schwann cells, instead, it regulates Schwann cell migration and adhesion. In addition to the ERK signaling pathway, FGFs can activate the phosphatidylinositide 3-kinase/Akt, phospholipase $\mathrm{C} \gamma, \mathrm{p} 38$, and JNK kinases, STAT1, STAT3 and STAT5 pathways (Ornitz and Itoh, 2015). These pathways could be activated in a cell type-dependent manner (Ornitz and Itoh, 2015). Our results of FGF5 regulates Schwann cell migration and adhesion indicated that FGF5 could activate other signaling pathways in Schwann cells rather than ERK1/2 signaling. Our findings further support the evidence that FGFs could stimulate the proliferation of some cells but inhibit the proliferation and promote the differentiation of others.

In this report, we identified an FGF5 autocrine function regulating Schwann cell migration and adhesion via the upregulation of $\mathrm{N}$-cadherin. Previous studies showed that $\mathrm{N}$-cadherin is expressed in cultured rat primary Schwann cells (Wanner and Wood, 2002; Roberts et al., 2017), and N-cadherin is upregulated in Schwann cells following peripheral nerve injury (Parrinello et al., 2010; Clements et al., 2017; Roberts et al., 2017). Studies have shown that Schwann cells in the peripheral nerves promote the repair of multiple tissue types including peripheral nerve gap bridging, skin wound healing and digit tip regeneration (Johnston et al., 2016; Carr and Johnston, 2017; Parfejevs et al., 2018; Jones et al., 2019). The injury-induced changes not only reprogram denervated Schwann cells into a repair cell state but also give them a highly motile phenotype. The importance of migrating Schwann cells in tissue regeneration is most evident in the cases of peripheral nerve transection injuries (Parrinello et al., 2010; Cattin et al., 2015; Dun et al., 2019). Following peripheral nerve transection injury, Schwann cells from both nerve end migrate into the nerve gap and form Schwann cell cords in the nerve bridge to guide axons regeneration. This Schwann cell migration property is key to successful peripheral nerve regeneration (Parrinello et al., 2010; Cattin et al., 2015; Chen et al., 2019; Dun and Parkinson, 2020). During the period of migration in the nerve bridge, Schwann cells contact each other through their long processes

\section{REFERENCES}

Aigouy, B., Lepelletier, L., and Giangrande, A. (2008). Glial chain migration requires pioneer cells. J. Neurosci. 28, 11635-11641. doi: 10.1523/JNEUROSCI. 1361-08.2008

Allodi, I., Mecollari, V., Gonzalez-Perez, F., Eggers, R., Hoyng, S., Verhaagen, J., et al. (2014). Schwann cells transduced with a lentiviral vector encoding Fgf-2 and form a chain to migrate toward the middle of the nerve bridge (Chen et al., 2019). Schwann cell migration in the nerve bridge appears as a classic example of cell chain migration, and this chain migration is important for the correct Schwann cell cord formation in the nerve bridge (Aigouy et al., 2008; Parrinello et al., 2010; Dun and Parkinson, 2015). Parrinello et al. (2010) reported that $\mathrm{N}$-cadherin is a key adhesion molecule in Schwann cells regulating chain formation in the nerve bridge during migration. Thus, our findings indicate that FGF5 could regulate $\mathrm{N}$-cadherin expression in migrating Schwann cells in the nerve bridge and promote Schwann cell chain formation.

In summary, we first systematically examined the expression of FGF5 and FGFR1-4 expression in Schwann cells of the mouse distal sciatic nerve and then investigated the effect of FGF5 treatment upon cultured primary rat Schwann cells. By microarray and mRNA sequencing data set analysis, RT-PCR, qPCR, western blot and immunostaining studies, we show that FGF5 is highly up-regulated in Schwann cells of the mouse distal sciatic nerve, and its receptors FGFR1 and FGFR2 are highly expressed in Schwann cells of the peripheral nerve both before and after injury. Using cultured primary rat Schwann cells, we revealed that FGF5 inhibits ERK1/2 activation but FGF5 regulates rapid Schwann cell migration and adhesion. Thus, FGF5 is an autocrine regulator of Schwann cell migration and adhesion. So far, Schwann cells are the best cell type that could be delivered into a nerve guidance conduit to promote peripheral nerve regeneration. Currently, cell delivery requires the use of collagen or a matrix gel to support cells inside the nerve guidance conduit. The use of collagen or matrix gel often decreases cell density and prevent cell-cell interaction and communication. We believe this FGF5 property of regulating Schwann cell adhesion could be utilized for Schwann cell delivery to prepare better engineered neural tissue for peripheral nerve repair.

\section{DATA AVAILABILITY STATEMENT}

All datasets presented in this study are included in the article.

\section{ETHICS STATEMENT}

The animal study was reviewed and approved by Plymouth University Animal Welfare and Ethical Review Board.

\section{AUTHOR CONTRIBUTIONS}

BC, RH, QM, and YL performed experiments and analyzed the data. XD designed the research. XD and DP wrote the article.

promote motor neuron regeneration following sciatic nerve injury. Glia 62, 1736-1746. doi: 10.1002/glia.22712

Barrette, B., Calvo, E., Vallieres, N., and Lacroix, S. (2010). Transcriptional profiling of the injured sciatic nerve of mice carrying the Wld(S) mutant gene: identification of genes involved in neuroprotection, neuroinflammation and nerve regeneration. Brain Behav. Immun. 24, 1254-1267. doi: 10.1016/j.bbi. 2010.07.249 
Beenken, A., and Mohammadi, M. (2009). The FGF family: biology, pathophysiology and therapy. Nat. Rev. Drug Discov. 8, 235-253. doi: $10.1038 / \mathrm{nrd} 2792$

Brockes, J. P., Fields, K. L., and Raff, M. C. (1979). Studies on cultured rat Schwann cells. I. Establishment of purified populations from cultures of peripheral nerve. Brain Res. 165, 105-118. doi: 10.1016/0006-8993(79)90048-9

Carr, M. J., and Johnston, A. P. (2017). Schwann cells as drivers of tissue repair and regeneration. Curr. Opin. Neurobiol. 47, 52-57. doi: 10.1016/j.conb.2017. 09.003

Carr, L., Parkinson, D. B., and Dun, X. P. (2017). Expression patterns of Slit and Robo family members in adult mouse spinal cord and peripheral nervous system. PLoS One 12:e0172736. doi: 10.1371/journal.pone.0172736

Cattin, A. L., Burden, J. J., Van Emmenis, L., Mackenzie, F. E., Hoving, J. J., Garcia Calavia, N., et al. (2015). Macrophage-induced blood vessels guide schwann cell-mediated regeneration of peripheral nerves. Cell 162, 1127-1139. doi: 10.1016/j.cell.2015.07.021

Charoenlarp, P., Rajendran, A. K., and Iseki, S. (2017). Role of fibroblast growth factors in bone regeneration. Inflamm. Regen. 37:10. doi: 10.1186/s41232-0170043-8

Chen, B., Chen, Q., Parkinson, D. B., and Dun, X. P. (2019). Analysis of schwann cell migration and axon regeneration following nerve injury in the sciatic nerve bridge. Front. Mol. Neurosci. 12:308. doi: 10.3389/fnmol.2019.00308

Clements, M. P., Byrne, E., Camarillo Guerrero, L. F., Cattin, A. L., Zakka, L., Ashraf, A., et al. (2017). The wound microenvironment reprograms schwann cells to invasive mesenchymal-like cells to drive peripheral nerve regeneration. Neuron 96, 98.e7-114.e7. doi: 10.1016/j.neuron.2017.09.008

Clements, D. A., Wang, J. K., Dionne, C. A., and Goldfarb, M. (1993). Activation of fibroblast growth factor (FGF) receptors by recombinant human FGF-5. Oncogene 8, 1311-1316.

Dierks, C., Mömke, S., Philipp, U., and Distl, O. (2013). Allelic heterogeneity of FGF5 mutations causes the long-hair phenotype in dogs. Anim. Genet. 44, 425-431. doi: 10.1111/age.12010

Dong, Z., Dean, C., Walters, J. E., Mirsky, R., and Jessen, K. R. (1997). Response of Schwann cells to mitogens in vitro is determined by pre-exposure to serum, time in vitro and developmental age. Glia 20, 219-230.

Drögemüller, C., Rüfenacht, S., Wichert, B., and Leeb, T. (2007). Mutations within the FGF5 gene are associated with hair length in cats. Anim. Genet. 38, 218-221. doi: 10.1111/j.1365-2052.2007.01590.x

Dun, X. P., Carr, L., Woodley, P. K., Barry, R. W., Drake, L. K., Mindos, T., et al. (2019). Macrophage-derived slit 3 controls cell migration and axon pathfinding in the peripheral nerve bridge. Cell Rep. 26, 1458.e4-1472.e4. doi: 10.1016/j. celrep.2018.12.081

Dun, X. P., and Parkinson, D. B. (2015). Visualizing peripheral nerve regeneration by whole mount staining. PLoS One 10:e0119168. doi: 10.1371/journal.pone. 0119168

Dun, X. P., and Parkinson, D. B. (2020). Classic axon guidance molecules control correct nerve bridge tissue formation and precise axon regeneration. Neural Regen. Res. 15, 6-9. doi: 10.4103/1673-5374.264441

Eckenstein, F. P., Shipley, G. D., and Nishi, R. (1991). Acidic and basic fibroblast growth factors in the nervous system: distribution and differential alteration of levels after injury of central versus peripheral nerve. J. Neurosci. 11, 412-419. doi: 10.1523/JNEUROSCI.11-02-00412.1991

Furusho, M., Dupree, J. L., Bryant, M., and Bansal, R. (2009). Disruption of fibroblast growth factor receptor signaling in nonmyelinating Schwann cells causes sensory axonal neuropathy and impairment of thermal pain sensitivity. J. Neurosci. 29, 1608-1614. doi: 10.1523/JNEUROSCI.5615-08.2009

Grothe, C., Haastert, K., and Jungnickel, J. (2006). Physiological function and putative therapeutic impact of the FGF-2 system in peripheral nerve regeneration--lessons from in vivo studies in mice and rats. Brain Res. Rev. 51, 293-299. doi: 10.1016/j.brainresrev.2005.12.001

Haub, O., Drucker, B., and Goldfarb, M. (1990). Expression of the murine fibroblast growth factor 5 gene in the adult central nervous system. Proc. Natl. Acad. Sci. U S A 87, 8022-8026. doi: 10.1073/pnas.87.20.8022

Haub, O., and Goldfarb, M. (1991). Expression of the fibroblast growth factor-5 gene in the mouse embryo. Development 112, 397-406.

Hébert, J. M., Rosenquist, T., Gotz, J., and Martin, G. R. (1994). FGF5 as a regulator of the hair growth cycle: evidence from targeted and spontaneous mutations. Cell 78, 1017-1025. doi: 10.1016/0092-8674(94)90276-3
Higgins, C. A., Petukhova, L., Harel, S., Ho, Y. Y., Drill, E., Shapiro, L., et al. (2014). FGF5 is a crucial regulator of hair length in humans. Proc. Natl. Acad. Sci. U S A 111, 10648-10653. doi: 10.1073/pnas.1402862111

Housley, D. J., and Venta, P. J. (2006). The long and the short of it: evidence that FGF5 is a major determinant of canine 'hair'-itability. Anim. Genet. 37, 309-315. doi: 10.1111/j.1365-2052.2006.01448.x

Hu, R., Fan, Z. Y., Wang, B. Y., Deng, S. L., Zhang, X. S., Zhang, J. L., et al. (2017). RAPID COMMUNICATION: generation of FGF5 knockout sheep via the CRISPR/Cas9 system. J. Anim. Sci. 95, 2019-2024. doi: 10.2527/jas. 2017.1503

Hughes, R. A., Sendtner, M., Goldfarb, M., Lindholm, D., and Thoenen, H. (1993). Evidence that fibroblast growth factor 5 is a major muscle-derived survival factor for cultured spinal motoneurons. Neuron 10, 369-377. doi: 10.1016/0896-6273(93)90327-n

Ishikawa, R., Nishikori, K., Furukawa, Y., Hayashi, K., and Furukawa, S. (1992). Injury-induced reduction of acidic fibroblast growth factor levels in the distal parts of rat sciatic nerve. Neurosci. Lett. 135, 113-116. doi: 10.1016/03043940(92) $90148-z$

Johnston, A. P., Yuzwa, S. A., Carr, M. J., Mahmud, N., Storer, M. A., Krause, M. P., et al. (2016). Dedifferentiated Schwann cell precursors secreting paracrine factors are required for regeneration of the Mammalian digit tip. Cell Stem Cell 19, 433-448. doi: 10.1016/j.stem.2016.06.002

Jones, R. E., Salhotra, A., Robertson, K. S., Ransom, R. C., Foster, D. S., Shah, H. N., et al. (2019). Skeletal stem cell-schwann cell circuitry in mandibular repair. Cell Rep. 28, 2757.e5-2766.e5. doi: 10.1016/j.celrep.2019.08.021

Jungnickel, J., Haase, K., Konitzer, J., Timmer, M., and Grothe, C. (2006). Faster nerve regeneration after sciatic nerve injury in mice over-expressing basic fibroblast growth factor. J. Neurobiol. 66, 940-948. doi: 10.1002/neu.20265

Kehler, J. S., David, V. A., Schaffer, A. A., Bajema, K., Eizirik, E., Ryugo, D. K., et al. (2007). Four independent mutations in the feline fibroblast growth factor 5 gene determine the long-haired phenotype in domestic cats. J. Hered. 98, 555-566. doi: 10.1093/jhered/esm072

Lebeau, P. F., Chen, J., Byun, J. H., Platko, K., and Austin, R. C. (2019). The trypan blue cellular debris assay: a novel low-cost method for the rapid quantification of cell death. MethodsX 6, 1174-1180. doi: 10.1016/j.mex.2019.05.010

Legrand, R., Tiret, L., and Abitbol, M. (2014). Two recessive mutations in FGF5 are associated with the long-hair phenotype in donkeys. Genet. Sel. Evol. 46:65. doi: 10.1186/s12711-014-0065-5

Li, W. R., Liu, C. X., Zhang, X. M., Chen, L., Peng, X. R., He, S. G., et al. (2017). CRISPR/Cas9-mediated loss of FGF5 function increases wool staple length in sheep. FEBS J. 284, 2764-2773. doi: 10.1111/febs.14144

Lindholm, D., Harikka, J., da Penha Berzaghi, M., Castren, E., Tzimagiorgis, G., Hughes, R. A., et al. (1994). Fibroblast growth factor-5 promotes differentiation of cultured rat septal cholinergic and raphe serotonergic neurons: comparison with the effects of neurotrophins. Eur. J. Neurosci. 6, 244-252. doi: 10.1111/j. 1460-9568.1994.tb00267.x

Livak, K. J., and Schmittgen, T. D. (2001). Analysis of relative gene expression data using real-time quantitative PCR and the $2^{-\Delta \Delta C T}$ method. Methods 25 , 402-408. doi: 10.1006/meth.2001.1262

Ma, K. H., Hung, H. A., and Svaren, J. (2016). Epigenomic regulation of Schwann cell reprogramming in peripheral nerve injury. J. Neurosci. 36, 9135-9147. doi: 10.1523/JNEUROSCI.1370-16.2016

Maddaluno, L., Urwyler, C., and Werner, S. (2017). Fibroblast growth factors: key players in regeneration and tissue repair. Development 144, 4047-4060. doi: $10.1242 /$ dev. 152587

Mallon, B. S., Shick, H. E., Kidd, G. J., and Macklin, W. B. (2002). Proteolipid promoter activity distinguishes two populations of NG2-positive cells throughout neonatal cortical development. J. Neurosci. 22, 876-885. doi: 10.1523/JNEUROSCI.22-03-00876.2002

Maurel, P. (2018). Preparation of neonatal rat schwann cells and embryonic dorsal root ganglia neurons for in vitro myelination studies. Methods Mol. Biol. 1739, 17-37. doi: 10.1007/978-1-4939-7649-2_2

McGeachie, A. B., Koishi, K., Imamura, T., and McLennan, I. S. (2001). Fibroblast growth factor-5 is expressed in Schwann cells and is not essential for motoneurone survival. Neuroscience 104, 891-899. doi: 10.1016/s03064522(01)00129-4

Meisinger, C., and Grothe, C. (1997). Differential regulation of fibroblast growth factor (FGF)-2 and FGF receptor 1 mRNAs and FGF-2 isoforms in spinal 
ganglia and sciatic nerve after peripheral nerve lesion. J. Neurochem. 68, 1150-1158. doi: 10.1046/j.1471-4159.1997.68031150.x

Moscoso, L. M., Cremer, H., and Sanes, J. R. (1998). Organization and reorganization of neuromuscular junctions in mice lacking neural cell adhesion molecule, tenascin-C, or fibroblast growth factor-5. J. Neurosci. 18, 1465-1477. doi: 10.1523/JNEUROSCI.18-04-01465.1998

Nunes, Q. M., Li, Y., Sun, C., Kinnunen, T. K., and Fernig, D. G. (2016). Fibroblast growth factors as tissue repair and regeneration therapeutics. PeerJ 4:e1535. doi: $10.7717 /$ peerj. 1535

Ornitz, D. M., and Itoh, N. (2015). The fibroblast growth factor signaling pathway. Wiley Interdiscip. Rev. Dev. Biol. 4, 215-266. doi: 10.1002/wdev.176

Pan, B., Liu, Y., Yan, J. Y., Wang, Y., Yao, X., Zhou, H. X., et al. (2016). Gene expression analysis at multiple time-points identifies key genes for nerve regeneration. Muscle Nerve 55, 373-383. doi: 10.1002/mus.25225

Parfejevs, V., Debbache, J., Shakhova, O., Schaefer, S. M., Glausch, M., Wegner, M., et al. (2018). Injury-activated glial cells promote wound healing of the adult skin in mice. Nat. Commun. 9:236. doi: 10.1038/s41467-017-01488-2

Parrinello, S., Napoli, I., Ribeiro, S., Wingfield Digby, P., Fedorova, M., Parkinson, D. B., et al. (2010). EphB signaling directs peripheral nerve regeneration through Sox2-dependent Schwann cell sorting. Cell 143, 145-155. doi: 10.1016/j.cell.2010.08.039

Pethö-Schramm, A., Müller, H. J., and Paus, R. (1996). FGF5 and the murine hair cycle. Arch. Dermatol. Res. 288, 264-266. doi: 10.1007/bf02530098

Roberts, S. L., Dun, X. P., Doddrell, R. D. S., Mindos, T., Drake, L. K., Onaitis, M. W., et al. (2017). Sox2 expression in Schwann cells inhibits myelination in vivo and induces influx of macrophages to the nerve. Development 144, 3114-3125. doi: 10.1242/jcs.210351

Scarlato, M., Xu, T., Bannerman, P., Beesley, J., Reddy, U. R., Rostami, A., et al. (2001). Axon-Schwann cell interactions regulate the expression of fibroblast growth factor-5 (FGF-5). J. Neurosci. Res. 66, 16-22. doi: 10.1002/jnr.1193

Stierli, S., Napoli, I., White, I. J., Cattin, A. L., Cabrejos, A. M., Calavia, N. G., et al. (2018). The regulation of the homeostasis and regeneration of peripheral nerve is distinct from the CNS and independent of a stem cell population. Development 145:dev170316. doi: 10.1242/dev.170316

Strober, W. (2015). Trypan blue exclusion test of cell viability. Curr. Protoc. Immunol. 111:1. doi: 10.1002/0471142735.ima03bs111

Tian, R., Yao, C., Yang, C., Zhu, Z., Li, C., Zhi, E., et al. (2019). Fibroblast growth factor-5 promotes spermatogonial stem cell proliferation via ERK and AKT activation. Stem Cell Res. Ther. 10:40. doi: 10.1186/s13287-019-1139-7

van Lieshout, E. M., Hougaard, D. M., and Larsson, L. I. (1995). Detection of primary and mature transcripts of calcitonin-gene-related peptide genes in rat parafollicular cells by light, fluorescence and confocal microscopy. Histochem. Cell Biol. 103, 19-24. doi: 10.1007/BF01464471

Wang, X., Cai, B., Zhou, J., Zhu, H., Niu, Y., Ma, B., et al. (2016). Correction: disruption of FGF5 in cashmere goats using CRISPR/Cas9 results in more secondary hair follicles and longer fibers. PLoS One 11:e0167322. doi: 10.1371/journal.pone.0167322

Wang, X., Yu, H., Lei, A., Zhou, J., Zeng, W., Zhu, H., et al. (2015). Generation of gene-modified goats targeting MSTN and FGF5 via zygote injection of CRISPR/Cas9 system. Sci. Rep. 5:13878. doi: 10.1038/srep13878

Wanner, I. B., and Wood, P. M. (2002). N-cadherin mediates axon-aligned process growth and cell-cell interaction in rat Schwann cells. J. Neurosci. 22, 4066-4079. doi: 10.1523/JNEUROSCI.22-10-04066.2002

Whim, M. D., and Moss, G. W. (2001). A novel technique that measures peptide secretion on a millisecond timescale reveals rapid changes in release. Neuron 30, 37-50. doi: 10.1016/s0896-6273(01)00261-6

Ydens, E., Cauwels, A., Asselbergh, B., Goethals, S., Peeraer, L., Lornet, G., et al. (2012). Acute injury in the peripheral nervous system triggers an alternative macrophage response. J. Neuroinflammation 9:176. doi: 10.1186/1742-20 94-9-176

Yoshizawa, Y., Wada, K., Shimoi, G., Kameyama, Y., Wakabayashi, Y., Fukuta, K., et al. (2015). A 1-bp deletion in Fgf5 causes male-dominant long hair in the Syrian hamster. Mamm. Genome 26, 630-637. doi: 10.1007/s00335-0159608-5

Yoshizawa, Y., Wada, K., Shimoi, G., Kameyama, Y., Wakabayashi, Y., Fukuta, K., et al. (2016). Erratum to: a 1-bp deletion in Fgf5 causes male-dominant long hair in the Syrian hamster. Mamm. Genome 27:98. doi: 10.1007/s00335-0159617-4

Yu, F., Liu, Z., Jiao, S., Zhang, X., Bai, C., Zhang, J., et al. (2018). A nonsense mutation in the FGF5 gene is associated with the long-haired phenotype in domestic guinea pigs (Cavia porcellus). Anim. Genet. 49:269. doi: 10.1111/age. 12656

Zhan, X., Bates, B., Hu, X. G., and Goldfarb, M. (1988). The human FGF-5 oncogene encodes a novel protein related to fibroblast growth factors. Mol. Cell. Biol. 8, 3487-3495. doi: 10.1128/mcb.8.8.3487

Zhan, X., Culpepper, A., Reddy, M., Loveless, J., and Goldfarb, M. (1987). Human oncogenes detected by a defined medium culture assay. Oncogene 1 , $369-376$

Conflict of Interest: The authors declare that the research was conducted in the absence of any commercial or financial relationships that could be construed as a potential conflict of interest.

Copyright $\odot 2020$ Chen, Hu, Min, Li, Parkinson and Dun. This is an open-access article distributed under the terms of the Creative Commons Attribution License (CC BY). The use, distribution or reproduction in other forums is permitted, provided the original author(s) and the copyright owner(s) are credited and that the original publication in this journal is cited, in accordance with accepted academic practice. No use, distribution or reproduction is permitted which does not comply with these terms. 